\title{
Obituary
}

\section{In memory of Prof. Dr. Sandro Forconi}

Professor Sandro Forconi, born 1938 in Siena, Italy, passed away in his home on the 15th of November, 2017. He was a past President of the Italian and the European Society of Hemorheology and Microcirculation, past and honorary Editor-in-Chief of Clinical Hemorheology and Microcirculation, and past recipient of the Fåhraeus Medal. He was an internationally known internal medicine physician, an estimated pioneer of Clinical Hemorheology, and a respected mentor for generations of young physicians in his home University in Siena. He was also an effortless champion of international cooperative programs: together with his wife Laura, he founded the Siena-Toronto center, which represented for over twenty years the most active international cooperation of the University of Siena. Among the guests of the Siena-Toronto center were, along with hundreds of students, the Governor General, the Foreign Affair minister, and numerous internationally acclaimed writers. In acknowledgement of the excellence of this cooperation, Laura and Sandro Forconi received the Arbor Award of the University of Toronto.

Sandro Forconi lived a full life with his enlarged family and was very much respected in his city. In 2006, his contrada, the Istrice, nominated him for the Mangia d'Oro, the most prestigious award of the city of Siena, which he received a year later.

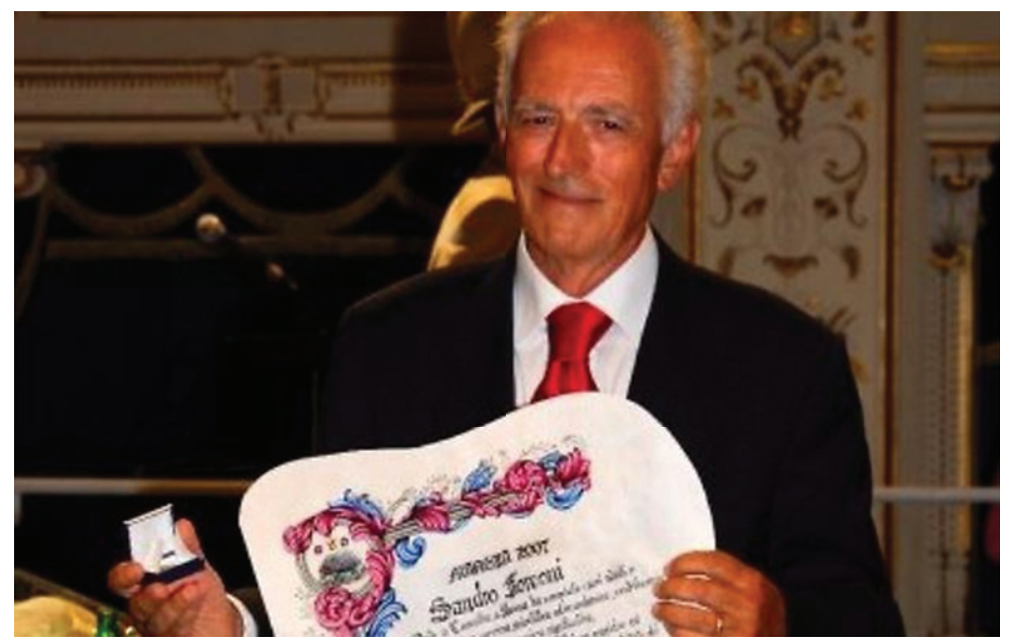

Prof. Sandro Forconi

As son of a physician, Prof. Forconi graduated 1962 in human medicine at the University of Siena, Italy, where he received his Abilitazione and later became Professor of Internal Medicine. He was founder of the Specialty school of Geriatrics, and Director of the Institute for Internal Medicine for many years. After his retirement, he became Emeritus in 2009.

Of all his works, he was proud of his classification of hyperviscosity syndromes, a classification that remains valid more than thirty years after he proposed and published it. Under his organization, Siena 
was home of two very successful Conferences of the European Society for Clinical Hemorheology and Microcirculation in 1995 and 2005. He always balanced the sometimes divergent aspirations in the European Society with his diplomacy and friendliness. The society and especially we all will miss this gentleman very much.

Professor Forconi will always be remembered as a husband, a father, a distinguished scientist, as well as a mentor and example for hundreds of fellows. His life was full of personal and professional achievements.

Requiescat in pace.

T. Gori

Zentrum für Kardiologie, University Hospital Mainz,

Mainz, Germany;

German Center for Cardiac and

Vascular Research (DZHK),

Standort Rhein-Main, Germany

\section{F. Jung}

Institute of Biomaterial Science and

Berlin-Brandenburg Centre for

Regenerative Therapies,

Helmholtz-Zentrum Geesthacht,

Kantstrasse 55,

14513, Teltow, Germany 